\title{
Optimization of Nutritional Variables Using Response Surface Methodology for Enhanced Antifungal Metabolite Production by Janibacter sp. RC18 from Turmeric Rhizosphere
}

\author{
Ruth Chiamaka Osaro-Matthew*, Francis Sopuruchukwu Ire and \\ Nnenna Frank-peterside
}

\author{
Department of Microbiology University of Port Harcourt Choba, Nigeria \\ *Corresponding author
}

\section{Keywords}

Janibacter sp. RC18, Antifungal metabolite, OFAT, Central composite design; Response surface methodology

\section{Article Info}

Accepted:

04 March 2020

Available Online:

10 April 2020

\section{A B S T R A C T}

Antifungal metabolites from rare actinomycetes have been found attractive for application due to its novelty, potency and environmental friendliness. Optimization of process variables for enhanced production of antifungal metabolite in Janibacter sp. RC18 was carried out in this study. One factor at a time (OFAT) was used for preliminary optimization of fermentation variables (time, temperature, initial $\mathrm{pH}$, carbon and nitrogen sources). A three factor central composite design (CCD) and response surface methodology (RSM) were employed for optimization of the selected significant nutritional variable (starch, soybean meal) and $\mathrm{CaCO}_{3}$. The optimum antifungal metabolite production was obtained at day 7 incubation period inhibition, temperature $30{ }^{\circ} \mathrm{C}, \mathrm{pH} 8$, starch as carbon source and soybean meal as nitrogen source. Response surface analysis revealed that the optimum value of the variables were $10.76 \mathrm{~g} / \mathrm{l}$ of starch, $11.95 \mathrm{~g} / \mathrm{l}$ of soybean meal and $1.57 \mathrm{~g} / \mathrm{l}$ of $\mathrm{CaCO}_{3}$. Under this optimal condition antifungal metabolite production was $23.7 \pm 0.09 \mathrm{~mm}$ which increased by $22.33 \%$ compared to OFAT optimized medium $(18.4 \pm 0.06 \mathrm{~mm})$. The present study has proved CCD and RSM is a reliable statistical tool for optimization of antifungal metabolite production in actinomycetes.

\section{Introduction}

The recent call for green or sustainable agriculture is a path to profitable and environmentally benign agriculture (FAO, 2017). The persistent use of synthetic agrochemicals leads to environmental and health problem. Most of these synthetic agrochemicals are recalcitrant xenobiotics persisting in the environment thereby causing environmental degradation. It also accumulates in the agricultural produce and can be passed to humans through food chain hence leading to health problems (EEA, 2005). 
Microorganisms have gained global attention as agroactive agents which are alternative to synthetic agrochemicals. Actinomycetes which are Gram positive bacteria have proved to be a promising microorganisms for production of various bioactive agent of agricultural importance (Ahmad et al., 2008). The genus Janibacter which Janibacter limosus was the first specie reported by Martin et al., (1997) belongs to the family intrasporangiaceae in the actinomycetales order. Some other species of this genus that have been reported are: J. terrae (Yoon et al., 2000), J. brevis (Imamura et al., 2000), J. melonis (Yoon et al., 2004), J. corallicola (Kageyama et al., 2007), J. hoylei (Shivaji et al., 2009), J. alkaliphilus (Li et al., 2012), J. cremeus (Hamada et al., 2013), and J. indicus Zhang et al., 2014). Some investigations have shown Janibacter as potential biocontrol agents, Janibacter melonis was reported to be antagonistic against Ralstonia solanacearum by Achari and Ramesh, (2014), and Nimaichand et al., (2015) reported Janibacter antagonistic against Fusarium oxysporum and Rhizoctonia oryzae-sativea.

In bioprospecting, one thing is to source for novel and potent strain another thing is sustainable production of bioactive metabolites by the strain. Antifungal metabolite production is affected by some physical (temperature, $\mathrm{pH}$ and incubation period) and nutritional factors (carbon, nitrogen and mineral) (Bundale et al., 2015). These factors are responsible to make fermentation conditions suitable for bacterial growth and metabolites production. Onefactor-at-a-time (OFAT) technique which is a traditional method of optimization that fails to describe interactions between variables and response is suitable for preliminary study in order to select significant factors before proceeding to optimization.

Although, identifying significant variables for optimal production of bioactive compound in a strain by OFAT is important. But for sustainability, variables especially nutritional factors should be incorporated at the correct levels, also relationship between the dependent and independent variables must be established hence the need for RSM optimization. Response surface methodology (RSM) which is a collection of mathematical and statistical tools is useful for analysing and optimizing response of multivariate system (Kocheki, 2009).

Hence the aim of this study is to use OFAT for preliminary optimization investigations, RSM and central composite design (CCD) to model and statistically optimize process variables for maximum antifungal production in Janibacter sp strain RC18.

\section{Materials and Methods}

\section{Actinomycetes and inoculum preparation}

Janibacter sp strain RC18 (Genbank Accession number MK473882) isolated from turmeric rhizosphere was described in precious studies (Osaro-Matthew et al., 2020). Strain RC18 was inoculated into $50 \mathrm{ml}$ Starch Casein broth in a $100 \mathrm{ml}$ Erlenmeyer flask. The flask was then incubated in a rotary incubator for $150 \mathrm{rpm}$ at temperature $30^{\circ} \mathrm{C}$ until absorbance of 0.2 was recorded at $\mathrm{OD}_{600}$ and $20 \mu \mathrm{l}$ of this culture was used as seed inoculum.

\section{Test phytopathogens}

Alternaria pimpriana DSM 62023 and Colletotrichum coccodes DSM 2492 were obtained from DSMZ (German collection of microorganism and cell cultures). Collectotricum coccodes DMS 2924 was selected as the test organism for RSM experiment since it is a commonly found phytopathogen in Nigeria. 


\section{Experimental set up}

The experiment was carried out in $100 \mathrm{ml}$ Erlenmeryer flask containing $50 \mathrm{ml}$ Glycerol beef extract broth of (Glycerol $10 \mathrm{~g} / \mathrm{l}$, Beef extract $10 \mathrm{~g} / \mathrm{l}, \mathrm{NaCl} 5 \mathrm{~g} / \mathrm{l}, \mathrm{CaCO}_{3} 2 \mathrm{~g} / \mathrm{l}$ and $\mathrm{K}_{2} \mathrm{HPO}_{4} 2.5 \mathrm{~g} / \mathrm{l}$,). Fermentation was carried out in a rotary incubator at $150 \mathrm{rpm}$, all experiment was done in triplicates.

\section{Bioassay}

At the end of fermentation, antifungal activity was determined using Agar well diffusion technique (Barry and Thornsberry, 1985), on a PDA (Potato Dextrose Agar). A $5 \mathrm{~mm}$ diameter well was made by punching the agar (inoculated with test organisms) with a sterile steel borer and $50 \mu \mathrm{l}$ of the culture supernatant obtained after centrifuging at $5000 \mathrm{rpm}$ for 10 minutes was poured in the well. Incubation was carried out at $25^{\circ} \mathrm{C} \pm 2$ ${ }^{\circ} \mathrm{C}$ for 5 days and the diameter zone of inhibition was measured and recorded in millimetres (mm).

\section{Selection of fermentation conditions Incubation period}

Fermentation media inoculated with strain $\mathrm{RC} 18$ were incubated at $28{ }^{\circ} \mathrm{C}$ on a rotary shaker for 10 days for maximum antifungal metabolite production and antifungal assay was carried out every 24 hours till the day 10 .

\section{Incubation temperature}

Effect of incubation temperatures on antifungal production of strain $\mathrm{RC} 18$ were studied at different temperature $\left(25^{\circ} \mathrm{C}, 30^{\circ} \mathrm{C}\right.$, $35{ }^{\circ} \mathrm{C}, 40{ }^{\circ} \mathrm{C}$ and $45{ }^{\circ} \mathrm{C}$ ). Fermentation was carried out in a Glycerol Beef extract (GBE) broth at the optimized fermentation period (day 7) and at the end bioassay was carried out as previously described.

\section{Initial pH}

Optimum $\mathrm{pH}$ was studied by adjusting initial fermentation media $\mathrm{pH}$ to different $\mathrm{pH}$ levels $(4,5,6,7,8,9,10)$ using $1 \mathrm{M} \mathrm{HCl}$ and $1 \mathrm{M}$ $\mathrm{NaOH}$. The fermentation broth was inoculated with strain $\mathrm{RC} 18$ and incubated at optimized temperature $\left(30^{\circ} \mathrm{C}\right)$ and optimized incubation period (7 days).

\section{Carbon sources}

To select the best carbon source for maximum antifungal metabolite production five different carbon sources (glucose, lactose, fructose, sucrose and starch) were used in substituting glycerol which was the carbon source in the primary basal medium one at a time. Afterward, fermentation was carried out at optimum temperature $\left(30{ }^{\circ} \mathrm{C}\right)$, incubation time (7 days) and $\mathrm{pH} 8$ and bioassay was carried as previously described.

\section{Nitrogen sources}

In order to select the best nitrogen sources for enhancing the antifungal activity of the strain RC18. Various sources of nitrogen (malt extract, yeast extract, peptone, ammonium sulphate, and soybean meal) were used to substitute one by one for beef extract (nitrogen source) in the primary basal medium and fermentation was carried out using the best carbon source (starch), at the optimum temperature $\left(30{ }^{\circ} \mathrm{C}\right.$ ), incubation time (7 days) and $\mathrm{pH} 8$, thereafter, bioassay was carried as previously described

\section{Experimental design for optimization by RSM}

\section{Central composite design}

The optimization of antifungal production was carried out according RSM. The nutritional variables were optimized for 
enhanced antifungal activity using the central composite design, the three selected variables were carbon, nitrogen and $\mathrm{CaCO}_{3}$. For carbon and nitrogen sources, starch and soybean meal were selected based on the one factor at a time result, for $\mathrm{CaCO}_{3}$ it was selected based on its role on slow growing actinomycetes.

The experimental runs comprise of 20 trials ( 8 factorial points, 6 axial points and 6 central point) based on the five-levels three variables. All fermentations were performed in a randomized order. RSM and second-order CCD for three-variables $\left(\right.$ Starch $=X_{1}$, Soybean meal $=\mathrm{X}_{2}$, and $\mathrm{CaCO}_{3}=\mathrm{X}_{3}$ ), five level combinations coded $-1.68,-1,0,+1$, and +1.68 as modelled by Snedecor and Cochran (1980) was adopted to determine the effects of the independent variables on response variables (antifungal activity). The natural levels were calculated using the coded levels as outlined in Table 1, comprising of 20 experimental runs and different formulation concentrations.

\section{Statistical and Mathematical Analysis}

Data obtained from one factor at a time optimization was subjected to ANOVA and mean were separated using Duncan multiple range test using SPSS. To determine if there is a relationship between the independent variables and the dependent variables for the RSM, regression method was used to analyse the obtained data using MINITAB 14.13. The response factor (Yi) as a mathematical function of a few continuous factors was modelled using regression analysis. A secondorder polynomial equation according to equation 1 was used to express the response.

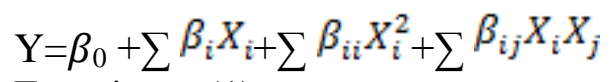

Equation (1)

$\mathrm{Y}$ represents the predicted response,,$_{0}$ is a constant $\beta_{i}$ is the coefficient of linear effect, $\beta_{\mathrm{ii}}$ is the coefficient squared effect, is the coefficient of interaction effect, and is independent variables under study. This design was used to study the effects of the variables (main, interaction, and quadratic). It was also used to optimize the levels of variables for enhancing antifungal activity. The developed model was then studied for significance and lack-of-fit, while response surface plot was designed after removal of the non-significant terms with the same software (Ahsan et al., 2017; Chirayu et al., 2018).

\section{Validation of the experimental model}

The prediction of the optimum concentration of starch, soybean and $\mathrm{CaCO}_{3}$ was achieved by applying the regression analysis of equation 1, the obtained optimal value was evaluated and compared to that of OFAT optimized medium of Starch soybean broth of (Soybean meal, $10 \mathrm{~g} / \mathrm{l}$, starch $10 \mathrm{~g} / \mathrm{l}, \mathrm{NaCl} 5$ $\mathrm{g} / \mathrm{l}$ and $\left.\mathrm{CaCO}_{3} 2 \mathrm{~g} / \mathrm{l}\right)$.

\section{Results and Discussion}

Time played an important role in the antimetabolite production in Janibacter $\mathrm{sp}$ RC18 (Fig. 1), it was observed that the incubation time for optimum production of antifungal metabolite in strain RC18 was day 7 with an inhibition zone of $15.0 \pm 0.58 \mathrm{~mm}$ against $C$. coccodes and $12.7 \pm 0.33 \mathrm{~mm}$ against $A$. pimpriana.

Janibacter sp RC18 was able to produce antifungal metabolite in the temperature range $20^{\circ} \mathrm{C}-40^{\circ} \mathrm{C}$, with an optimum at $30^{\circ} \mathrm{C}$ and no activity at $45^{\circ} \mathrm{C}$ (Fig. 2).

The effect of $\mathrm{pH}$ levels variation on antifungal metabolite production of strain $\mathrm{RC} 18$ as represented in (Fig. 3) showed that $\mathrm{pH} 8$ was optimal as $14.8 \pm 0.17 \mathrm{~mm}$ inhibition zone was obtained against $C$. coccodes and $15.8 \pm$ $0.33 \mathrm{~mm}$ inhibition zone was obtained against 
A. pimpriana. The minimum antifungal metabolite production was obtained at $\mathrm{pH} 6$ while there was no antifungal production at $\mathrm{pH} 4,5$ and 10.

Optimum antifungal production was obtained when starch was used as sole carbon source as presented in (Fig. 4). Soybean meal was the best nitrogen source for antifungal production in strain RC18 (Fig. 5).

RSM optimization of process variable by CCD

The study adopted RSM using CCD in which 20 experimental runs to enable adequate measurement of the response variables (antifungal metabolite production) were performed as presented in Table 2 .

The coded coefficient for antifungal production in Janibacter sp RC18 was presented in Table 3. The linear, interactive and quadratic effects of 3 independent variables starch $\left(\mathrm{X}_{1}\right)$ soybean $\left(\mathrm{X}_{2}\right)$ and $\mathrm{CaCO}_{3}$ $\left(\mathrm{X}_{3}\right)$ at three levels on the response variable (antifungal production) of Janibacter $\mathrm{sp}$ RC18 were reported. The linear effects were all significant at $(P<0.001)$, the quadratic effect of $\mathrm{X}_{1} \mathrm{X}_{2}$ (starch and soybean meal) was not significant. The T-value of $\mathrm{X}_{3}$ and quadratic effect of the three variables were negative which indicates negative correlation.

From the analysis of variance (ANOVA) (Table 4 ) the model showed a high $F$-value (349.27), a small p-value (0.000), a non significant Lack of fit (0.509), Coefficient of Variation (0.324070), coefficient of determination $\left(\mathrm{R}^{2}\right)$ value $99.68 \%$ and adjusted $R^{2}\left(R^{2}\right.$ adj) value $99.40 \%$.

\section{Analysis of residual to check regression assumptions}

The graphical validation of the regression model using residual plots residual plot were presented in Fig. 6a-d. The normal probability plot showed linearity (Fig. 6a), the plots of residual versus fitted value (Fig. 6b) randomly scattered around 0 point. The plot of frequency versus residual (Fig. 6c) histogram showed a dumbbell shaped. The plot of residual versus observation order in (Fig. 6d) showed a symmetric pattern.

\section{Response surface and contour plots}

The 3D response surface and 2D contour plots of Janibacter sp. RC18 antifungal activity against Collectotricum coccodes are shown in Figure 7. The 2D contour plots of (Fig. 7a., Fig. 7c.) representing the interactive effect of starch and soybean meal, and starch and $\mathrm{CaCO}_{3}$ were elliptical in shape. The interactive effect of soybean meal and $\mathrm{CaCO}_{3}$ was circular in shape (Fig. 7e).

The three dimensional (3D) RSM plots (Fig. $7 \mathrm{~b}, 7 \mathrm{~d}, 7 \mathrm{f}$.$) indicated that maximum$ antifungal activity occurred at medium level of soybean meal $(10-14 \mathrm{~g} / \mathrm{l}), \mathrm{CaCO}_{3}(1-2.5$ $\mathrm{g} / \mathrm{l})$ and starch $(10-12 \mathrm{~g} / \mathrm{l})$.

\section{Prediction of optimal level}

The optimal plot (Fig. 8) displays the prediction of the optimal level based on the result of the regression model above. The optimal value of the response variable 24.48 mm was obtained with Carbon, Nitrogen and $\mathrm{CaCO}_{3}$ source as $10.76 \mathrm{~g} / 1,11.95 \mathrm{~g} / \mathrm{l}$ and 1.57 $\mathrm{g} / \mathrm{l}$ respectively.

\section{Correlation between the observed} antifungal activity and the predicted values

The correlation between the observed antifungal activity and the RSM predicted values as represented in the parity plot. Figure 9 shows that from the experimental tests that the observed values were close to the predicted value. 
Table.1 Coded and uncoded value for each variable

\begin{tabular}{|c|c|c|c|c|c|c|}
\hline \multicolumn{2}{|c|}{ Variables } & \multicolumn{5}{c|}{ Coded levels of experimental variables } \\
\hline Coded & Uncoded & $-\alpha$ & -1 & 0 & +1 & $+\alpha$ \\
\hline $\mathrm{X}_{1}$ & Starch & 1.59 & 5 & 10 & 15 & 18.41 \\
\hline $\mathrm{X}_{2}$ & Soybean meal & 1.59 & 5 & 10 & 15 & 18.41 \\
\hline $\mathrm{X}_{3}$ & $\mathrm{CaCO}_{3}$ & 0.32 & 1 & 2 & 3 & 3.68 \\
\hline
\end{tabular}

Table. 2 Central composite design plan in coded value, the observed and predicted response

\begin{tabular}{|c|c|c|c|c|c|}
\hline \multirow[t]{2}{*}{ Run } & \multirow[t]{2}{*}{$\begin{array}{c}\mathrm{X}_{1}: \text { Starch } \\
\quad(\mathrm{g} / \mathrm{L})\end{array}$} & \multirow[t]{2}{*}{$\begin{array}{l}\mathrm{X}_{2} \text { : Soy bean } \\
\text { meal }(\mathrm{g} / \mathrm{L})\end{array}$} & \multirow[t]{2}{*}{$\begin{array}{l}\mathrm{X} 3: \mathrm{CaCO}_{3} \\
\quad(\mathrm{~g} / \mathrm{L})\end{array}$} & \multicolumn{2}{|c|}{$\begin{array}{l}\text { Inhibition Zone diameter } \\
(\mathrm{mm})\end{array}$} \\
\hline & & & & Observed & Predicted \\
\hline 1 & -1 & 1 & -1 & 22.30 & 22.15 \\
\hline 2 & 0 & -1.68 & 0 & 13.70 & 13.26 \\
\hline 3 & 0 & 0 & 0 & 22.40 & 23.60 \\
\hline 4 & 1 & 1 & 1 & 18.60 & 18.14 \\
\hline 5 & 1 & -1 & 1 & 15.00 & 15.21 \\
\hline 6 & 0 & 0 & 0 & 23.60 & 23.60 \\
\hline 7 & -1 & -1 & 1 & 12.00 & 11.98 \\
\hline 8 & -1 & -1 & -1 & 17.30 & 17.82 \\
\hline 9 & 0 & 0 & 0 & 22.70 & 23.60 \\
\hline 10 & 0 & 0 & 0 & 23.40 & 23.60 \\
\hline 11 & -1 & 1 & 1 & 14.50 & 14.46 \\
\hline 12 & 1 & 1 & -1 & 21.50 & 21.58 \\
\hline 13 & 1 & -1 & -1 & 16.70 & 16.79 \\
\hline 14 & 0 & 0 & 1.68 & 11.50 & 11.71 \\
\hline 15 & 0 & 0 & -1.68 & 19.80 & 19.51 \\
\hline 16 & 1.68 & 0 & 0 & 22.00 & 22.08 \\
\hline 17 & 0 & 0 & 0 & 23.00 & 23.60 \\
\hline 18 & -1.68 & 0 & 0 & 20.00 & 19.84 \\
\hline 19 & 0 & 1.68 & 0 & 19.00 & 19.37 \\
\hline 20 & 0 & 0 & 0 & 23.90 & 23.60 \\
\hline
\end{tabular}


Table.3 Coded Coefficient for Antifungal Production

\begin{tabular}{|l|c|c|c|c|c|c|}
\hline Term & Effect & Coef & SE Coef & T-Value & P-Value & VIF \\
\hline Constant & & 21.512 & 0.131 & 164.16 & 0.000 & \\
\hline $\mathrm{X}_{1}$ & 1.5413 & 0.7706 & 0.0676 & 11.41 & 0.000 & 2.37 \\
\hline $\mathrm{X}_{2}$ & 4.3386 & 2.1693 & 0.0676 & 32.11 & 0.000 & 2.37 \\
\hline $\mathrm{X}_{3}$ & -5.236 & -2.618 & 0.119 & -21.93 & 0.000 & 1.85 \\
\hline $\mathrm{X}_{1}{ }^{2}$ & -0.4669 & -0.2335 & 0.0213 & -10.94 & 0.000 & 1.97 \\
\hline $\mathrm{X}_{2}{ }^{2}$ & -1.2889 & -0.6445 & 0.0213 & -30.20 & 0.000 & 1.97 \\
\hline $\mathrm{X}_{3}{ }^{2}$ & -5.6507 & -2.8254 & 0.0854 & -33.10 & 0.000 & 1.02 \\
\hline $\mathrm{X}_{1} \mathrm{X}_{2}$ & 0.0563 & 0.0281 & 0.0286 & 0.98 & 0.349 & 1.85 \\
\hline $\mathrm{X}_{1} \mathrm{X}_{3}$ & 1.0625 & 0.5312 & 0.0573 & 9.27 & 0.000 & 1.43 \\
\hline $\mathrm{X}_{2} \mathrm{X}_{3}$ & 0.4625 & -0.2313 & 0.0573 & -4.04 & 0.002 & 1.43 \\
\hline
\end{tabular}

Coef. $=$ coefficient.

Table.4 Analysis of Variance (ANOVA) for Quadratic Model

\begin{tabular}{|l|c|c|c|c|c|}
\hline SOURCES & $\mathrm{DF}$ & $\mathrm{SS}$ & $\mathrm{MS}$ & $F$-value & $P$-value \\
\hline Model & 9 & 330.107 & 36.679 & 349.25 & 0.000 \\
\hline Linear & 3 & 160.869 & 53.623 & 510.59 & 0.000 \\
\hline $\mathrm{X}_{1}$ & 1 & 13.663 & 13.663 & 130.10 & 0.000 \\
\hline $\mathrm{X}_{2}$ & 1 & 108.263 & 108.263 & 1030.87 & 0.000 \\
\hline $\mathrm{X}_{3}$ & 1 & 50.506 & 50.506 & 480.91 & 0.000 \\
\hline Square & 3 & 194.773 & 64.924 & 618.20 & 0.000 \\
\hline $\mathrm{X}_{1}{ }^{2}$ & 1 & 12.568 & 12.568 & 119.67 & 0.000 \\
\hline $\mathrm{X}_{2}{ }^{2}$ & 1 & 95.769 & 95.769 & 911.90 & 0.000 \\
\hline $\mathrm{X}_{3}{ }^{2}$ & 1 & 115.041 & 115.041 & 1095.40 & 0.000 \\
\hline 2 -Way Interaction & 3 & 10.844 & 3.615 & 34.42 & 0.000 \\
\hline $\mathrm{X}_{1} \mathrm{X}_{2}$ & 1 & 0.101 & 0.101 & 0.96 & $0.349^{\text {ns }}$ \\
\hline $\mathrm{X}_{1} \mathrm{X}_{3}$ & 1 & 9.031 & 9.031 & 85.99 & 0.000 \\
\hline $\mathrm{X}_{2} \mathrm{X}_{3}$ & 1 & 1.711 & 1.711 & 16.29 & 0.002 \\
\hline Error & 10 & 1.050 & 0.105 & & \\
\hline Lack-of-Fit & 5 & 1.050 & 0.210 & 5.00 & $0.0509^{\text {ns }}$ \\
\hline Pure Error & 5 & 0.030 & 0.001 & & \\
\hline Total & 19 & 331.157 & & & \\
\hline
\end{tabular}

$R^{2}=0.9968$; significant at $P$ value less than 0.05 . ns $=$ non-significant.

Model Summary $=$ C.V. $($ coefficient of variation $)=0.324070$

$\mathrm{R}^{2}(99.68 \%) \quad \mathrm{R}^{2}$ (adjusted) (99.40\%) $\mathrm{R}^{2}$ (predicted) (97.49\%). 


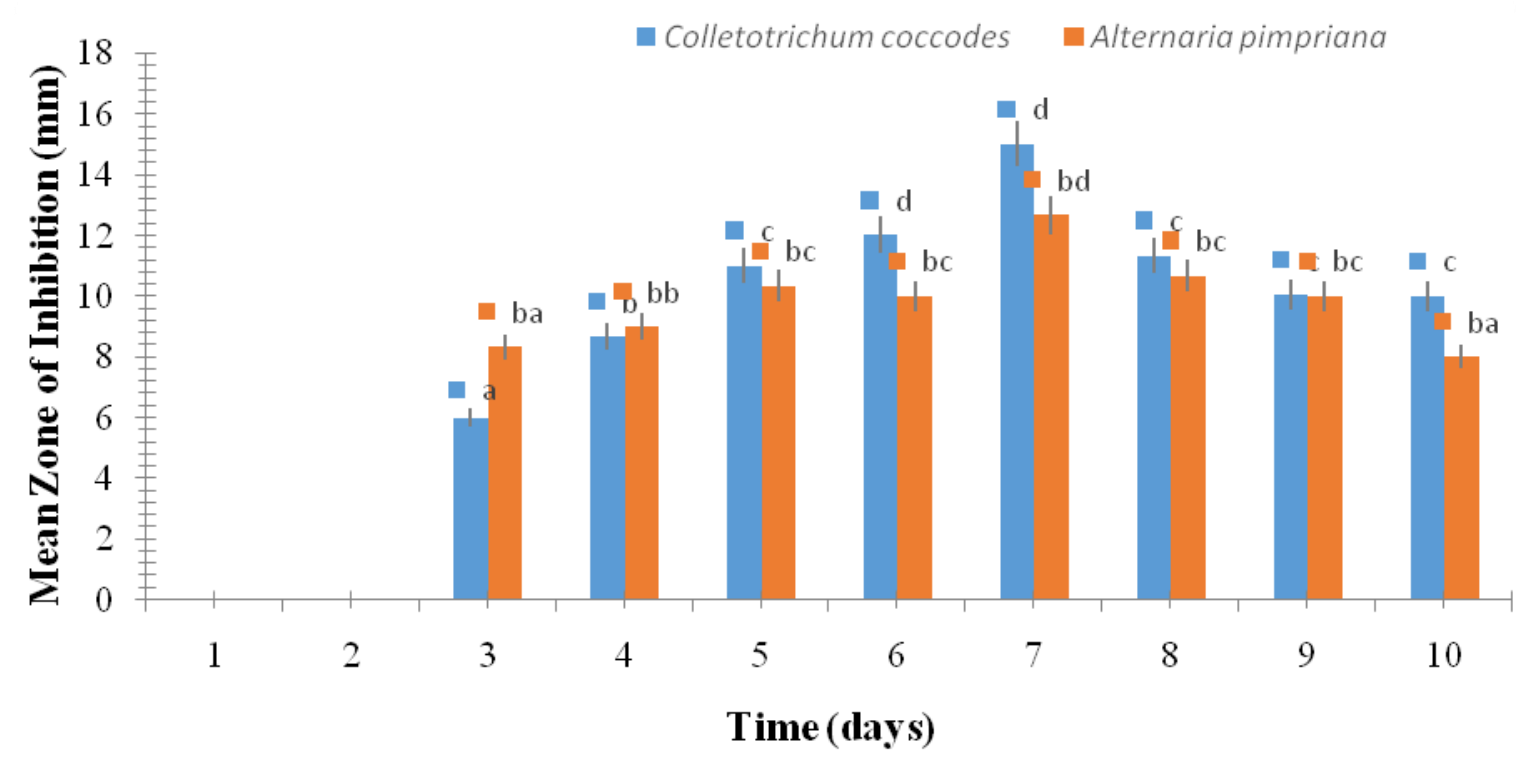

Fig. 1: Effect of incubation period on antifungal metabolite production by Janibacter sp. RC18

Bars represent mean \pm SE of three replicates. Different letters on bars indicates significant difference between treatments, Using Duncan's multiple range test $(P \leq 0.05)$.

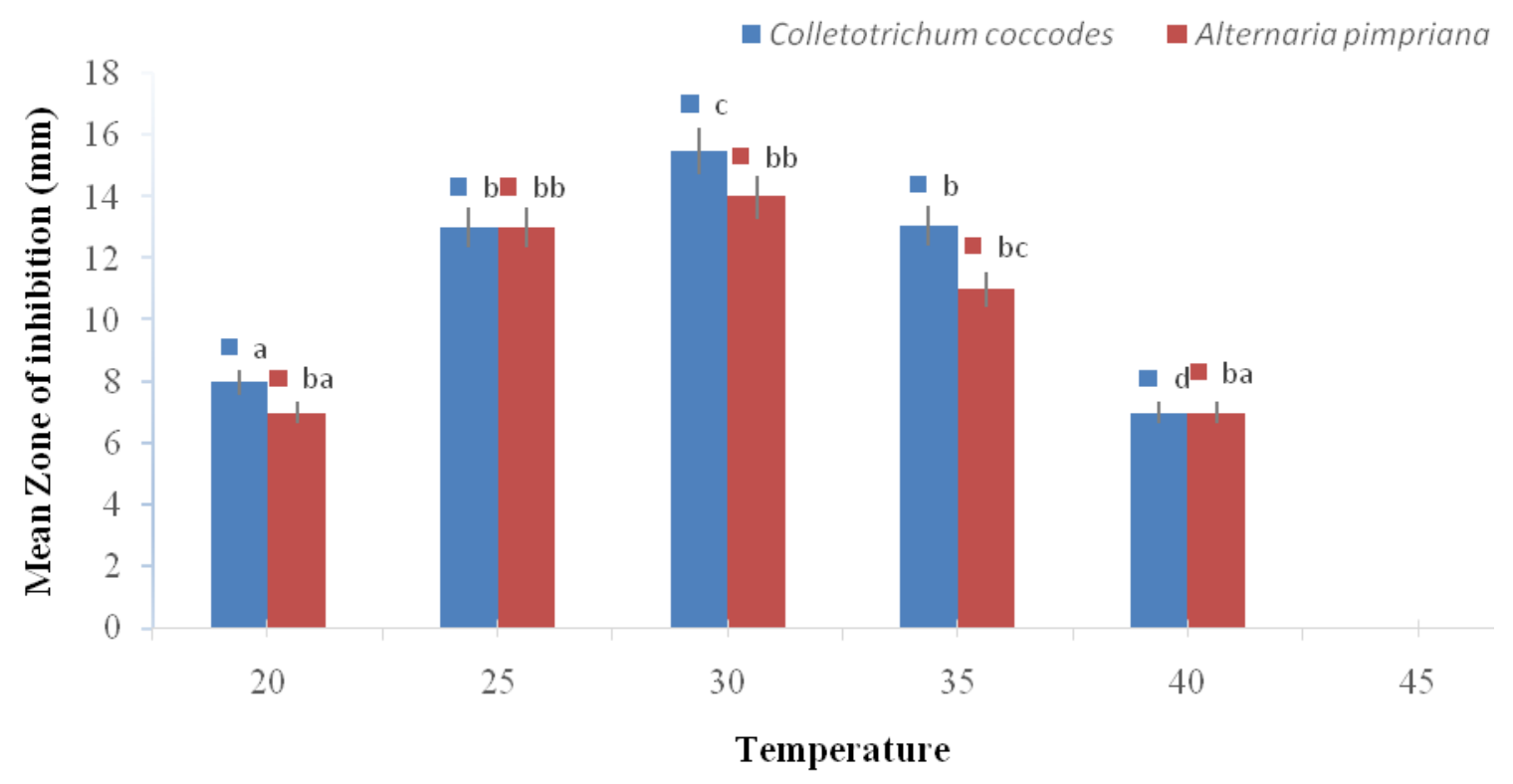

Fig. 2: Effect of incubation temperature on antifungal metaboliteproduction by Janibacter sp. RC18

Bars represent mean $\pm \mathrm{SE}$ of three replicates. Different letters on bars indicates significant difference between treatments, Using Duncan's multiple range test $(P \leq 0.05)$. 


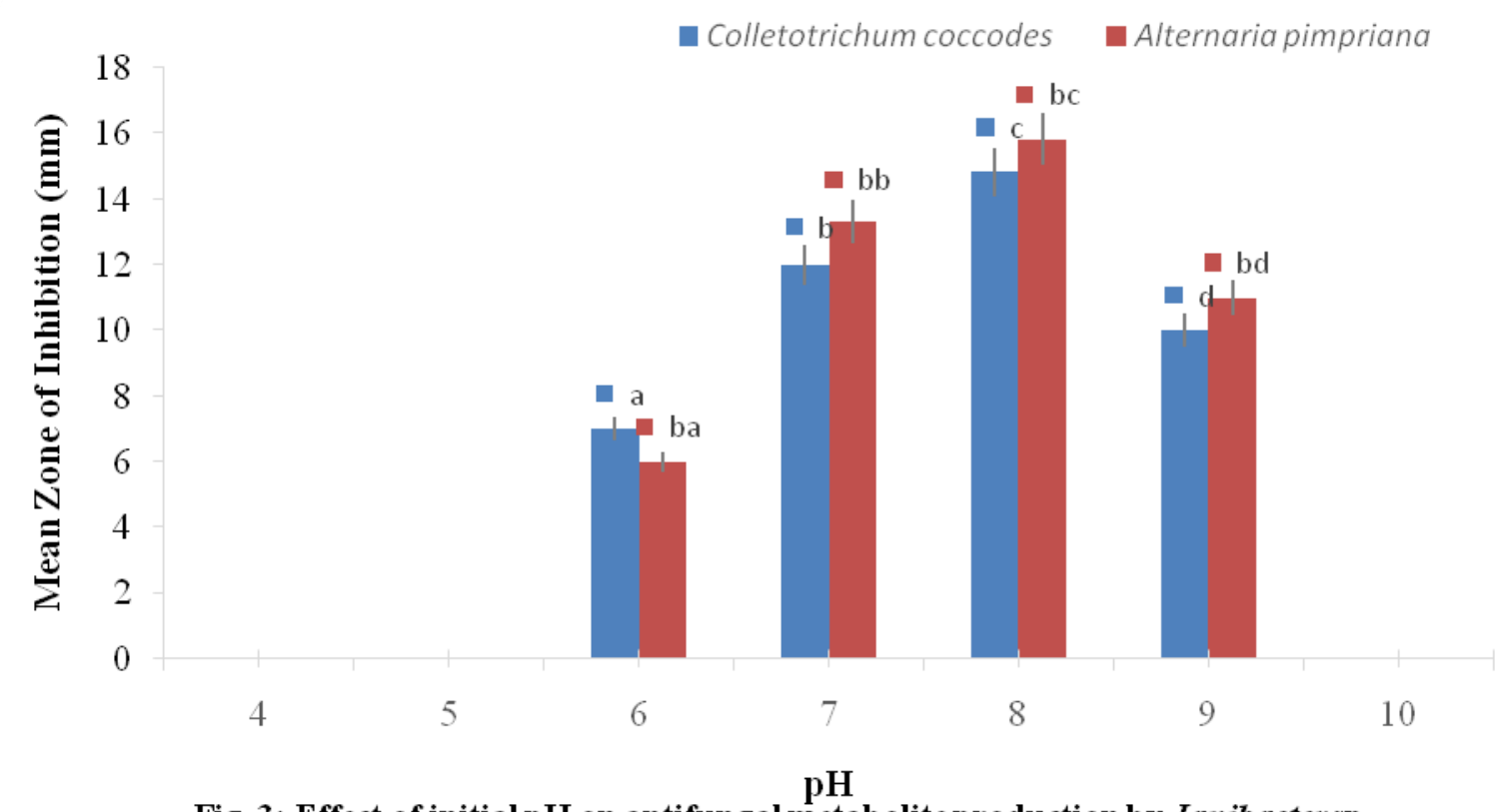

Fig. 3: Effect of initial pH on antifungal metab olite production by Janibacter sp. RC18

Bars represent mean $\pm \mathrm{SE}$ of three replicates. Different letters on bars indicates significant difference between treatments, Using Duncan's multiple range test $(P \leq 0.05)$.

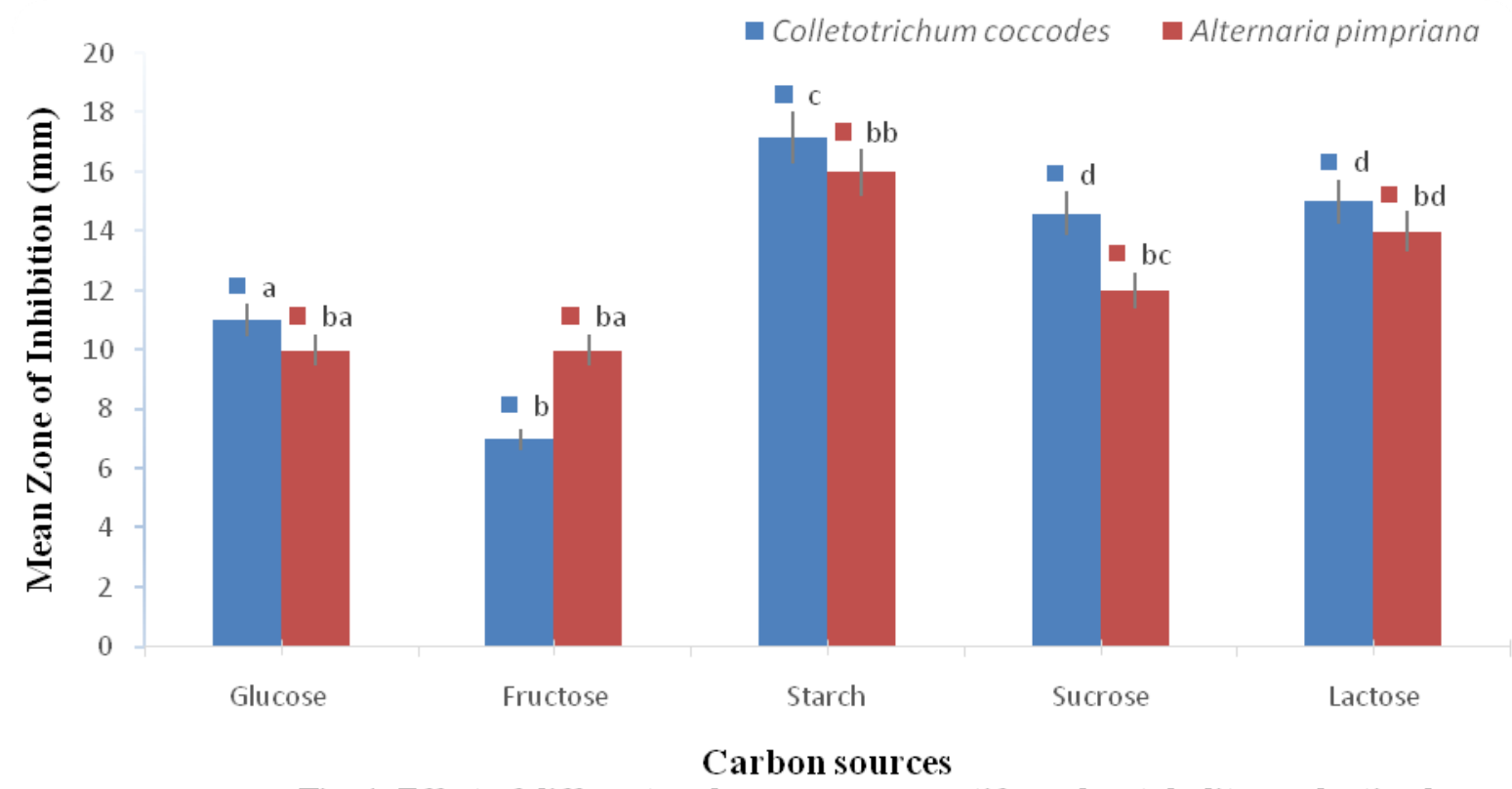

Fig. 4: Effect of different carbon sources on antifungal metabolite production by Janibacter sp. RC18

Bars represent mean $\pm \mathrm{SE}$ of three replicates. Different letters on bars indicates significant difference between treatments, Using Duncan's multiple range test $(P \leq 0.05)$. 


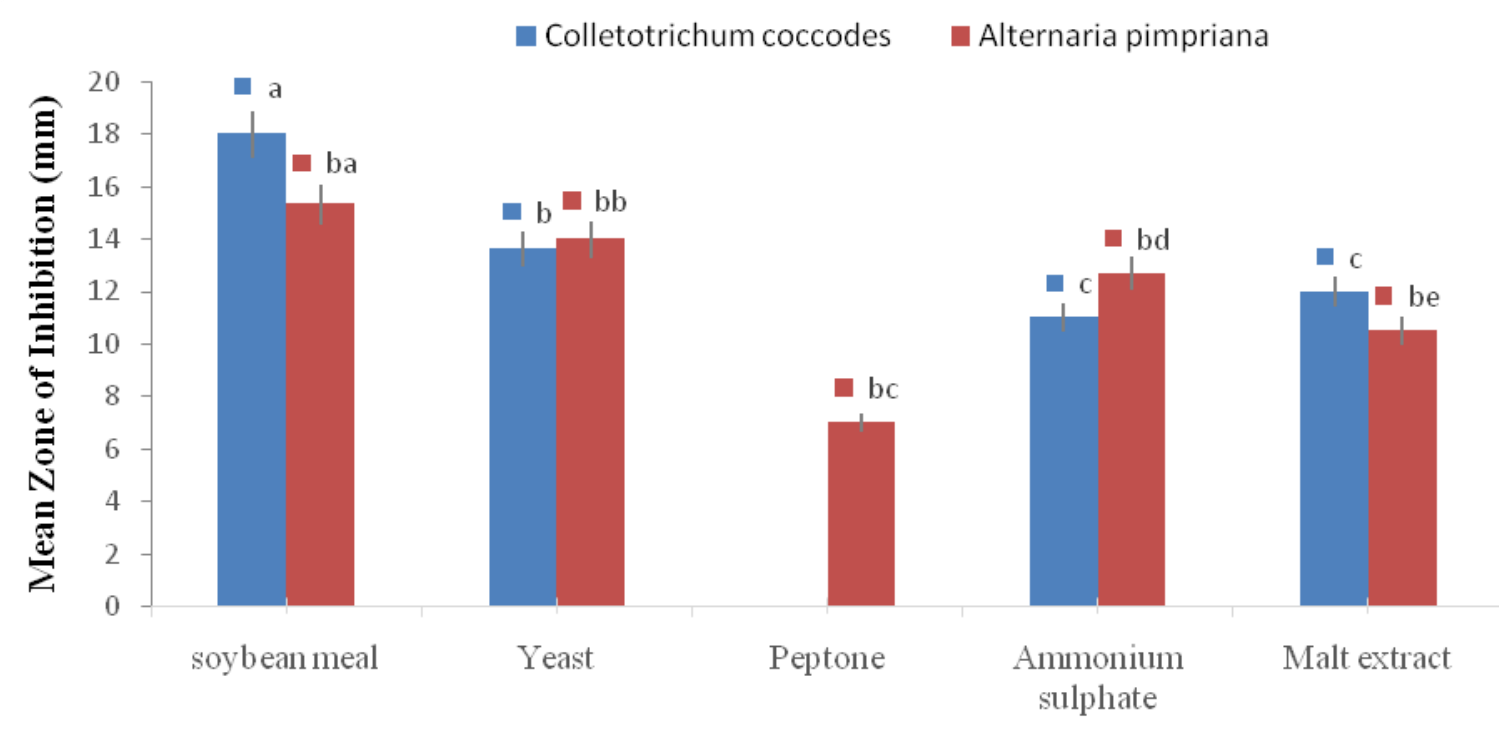

Nitrogen Sources

Fig. 5: Effect of nitrogen sources on antifungal metaboliteproduction by Janibacter sp. RC18

Bars represent mean \pm SE of three replicates. Different letters on bars indicates significant difference between treatments, Using Duncan's multiple range test $(P \leq 0.05)$.

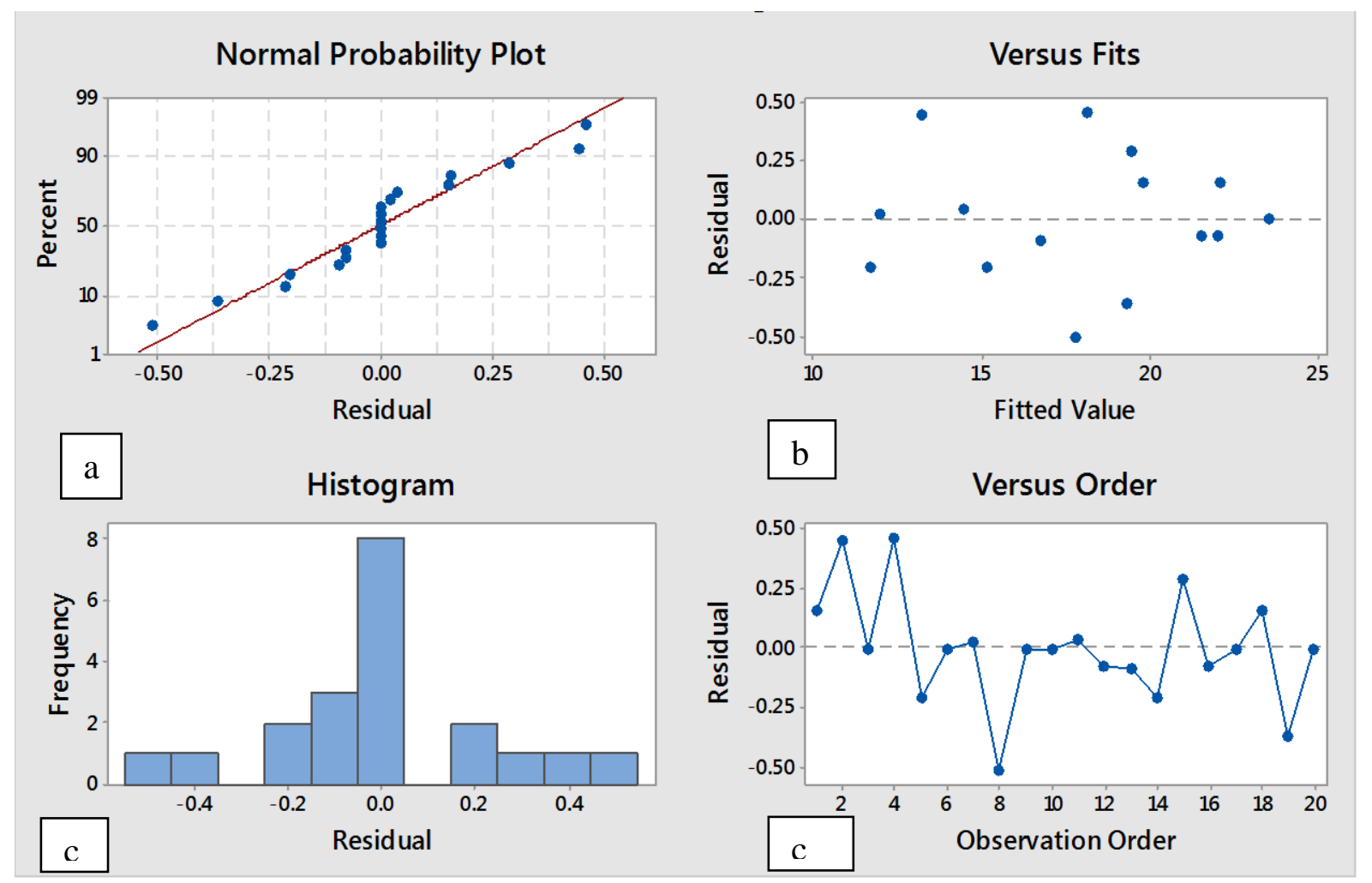

Fig.6 Residual plot for Antifungal activity (mm)

a) Normal probability plot. (b) plot of residual versus fitted value (c) histogram of residual (d) Residual versus observed order. 


\section{Int.J.Curr.Microbiol.App.Sci (2020) 9(4): 284-302}
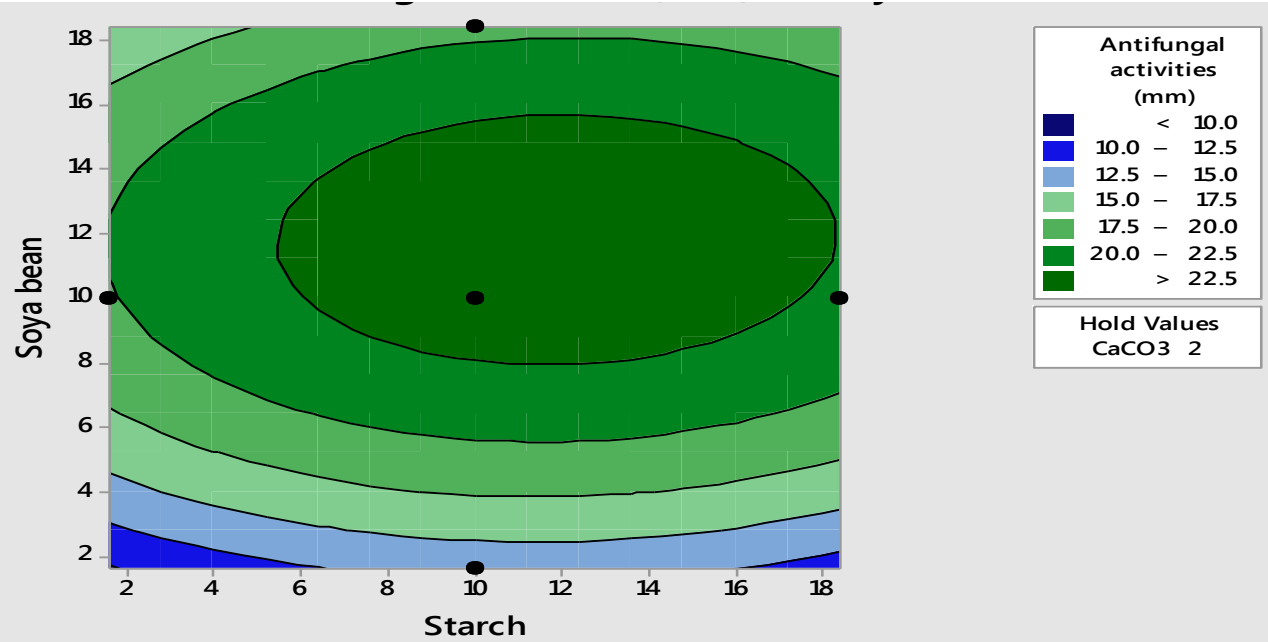

(a)

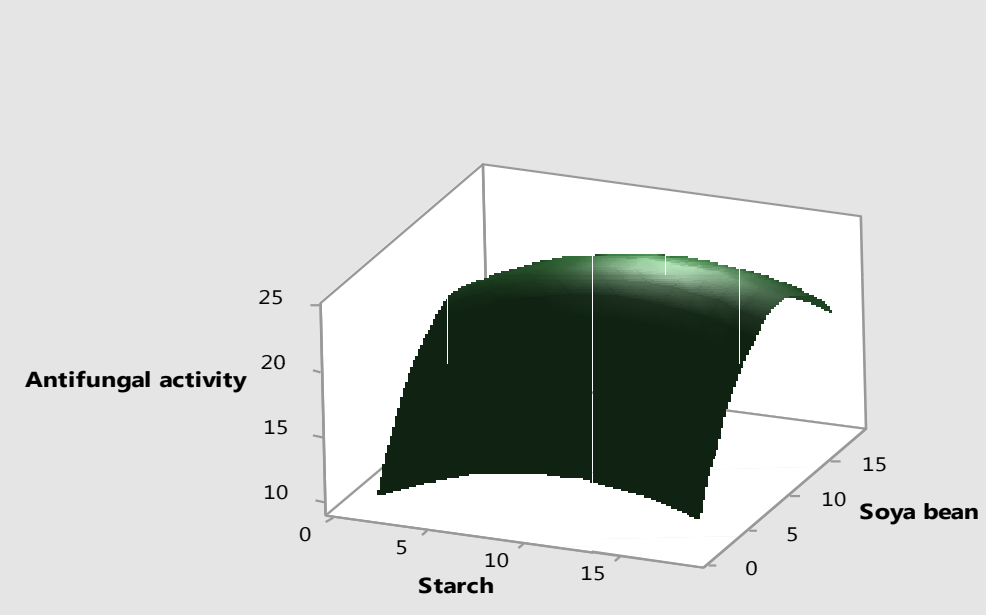

Hold Values $\mathrm{CaCO} 32$

(b)
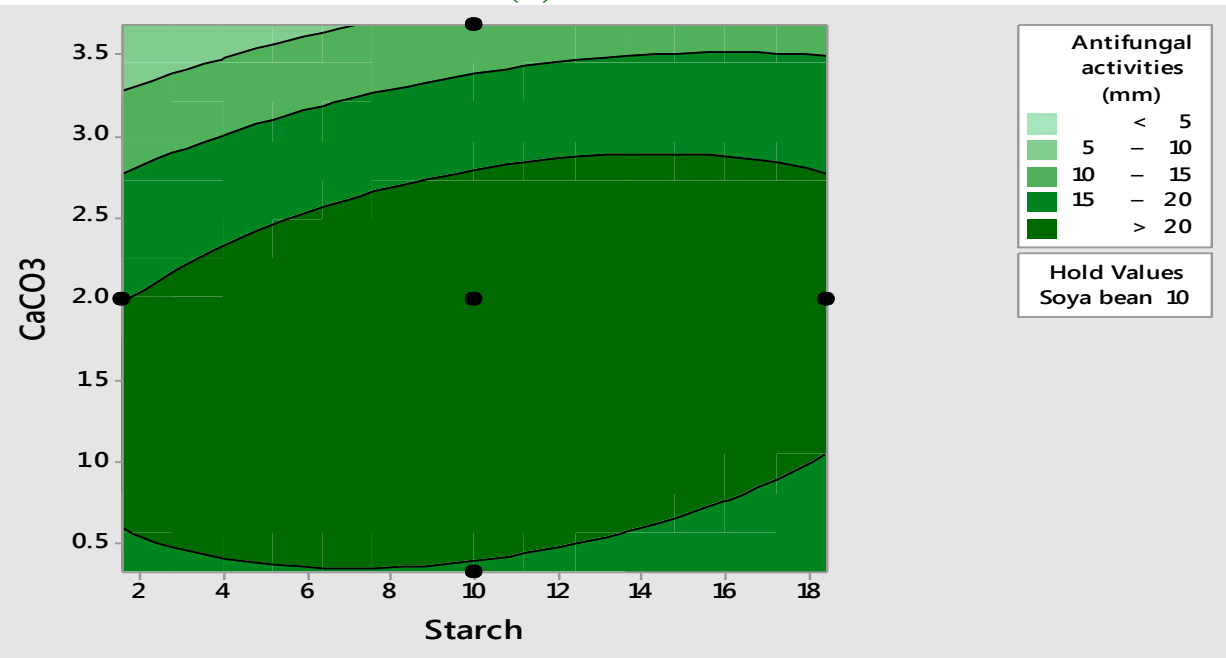

(c) 


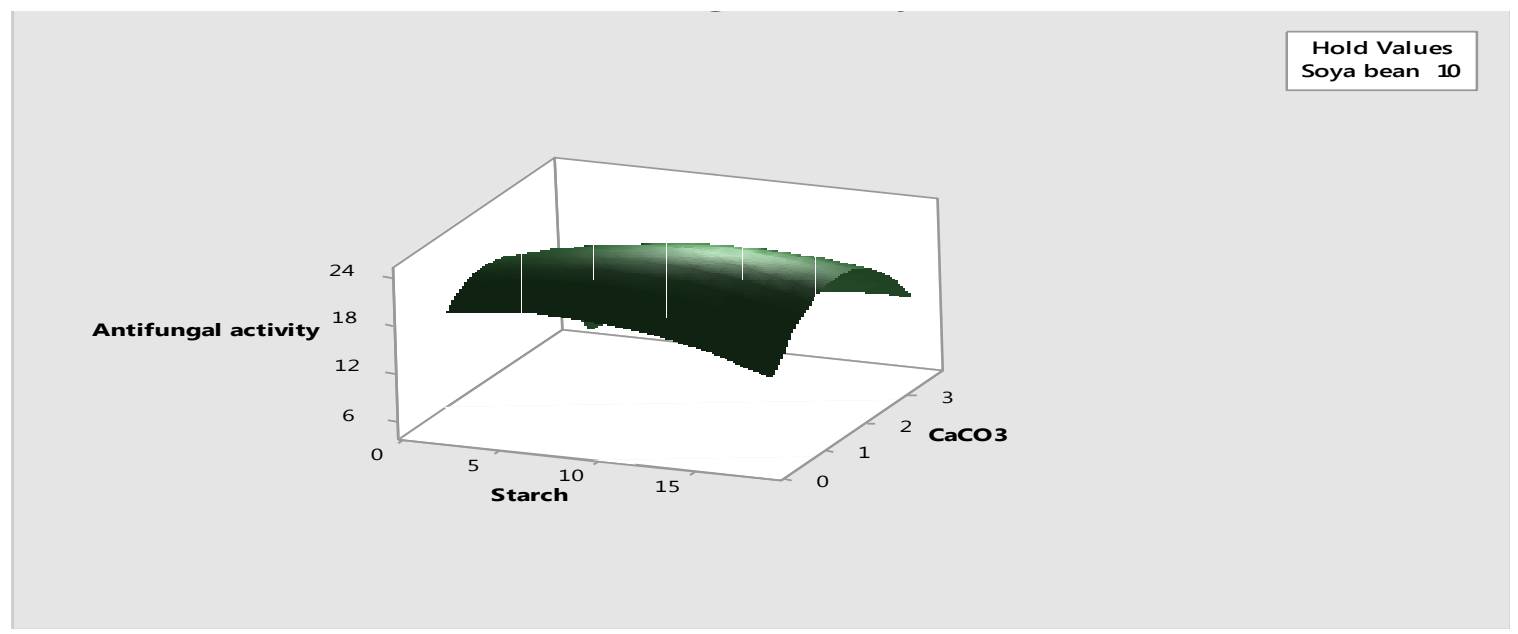

(d)
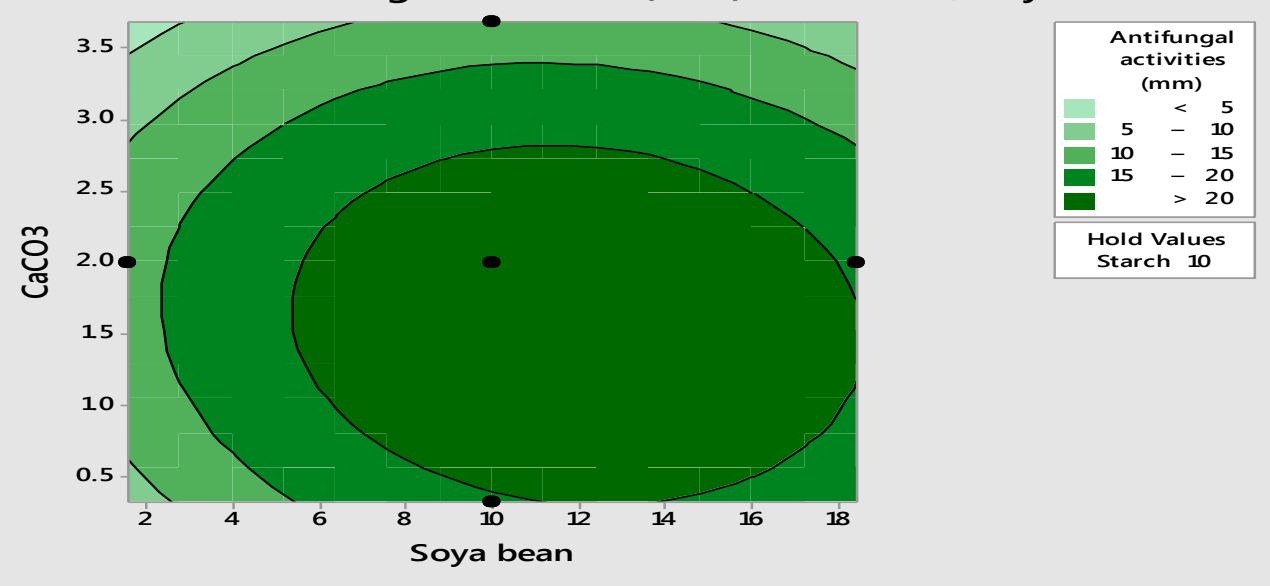

(e)

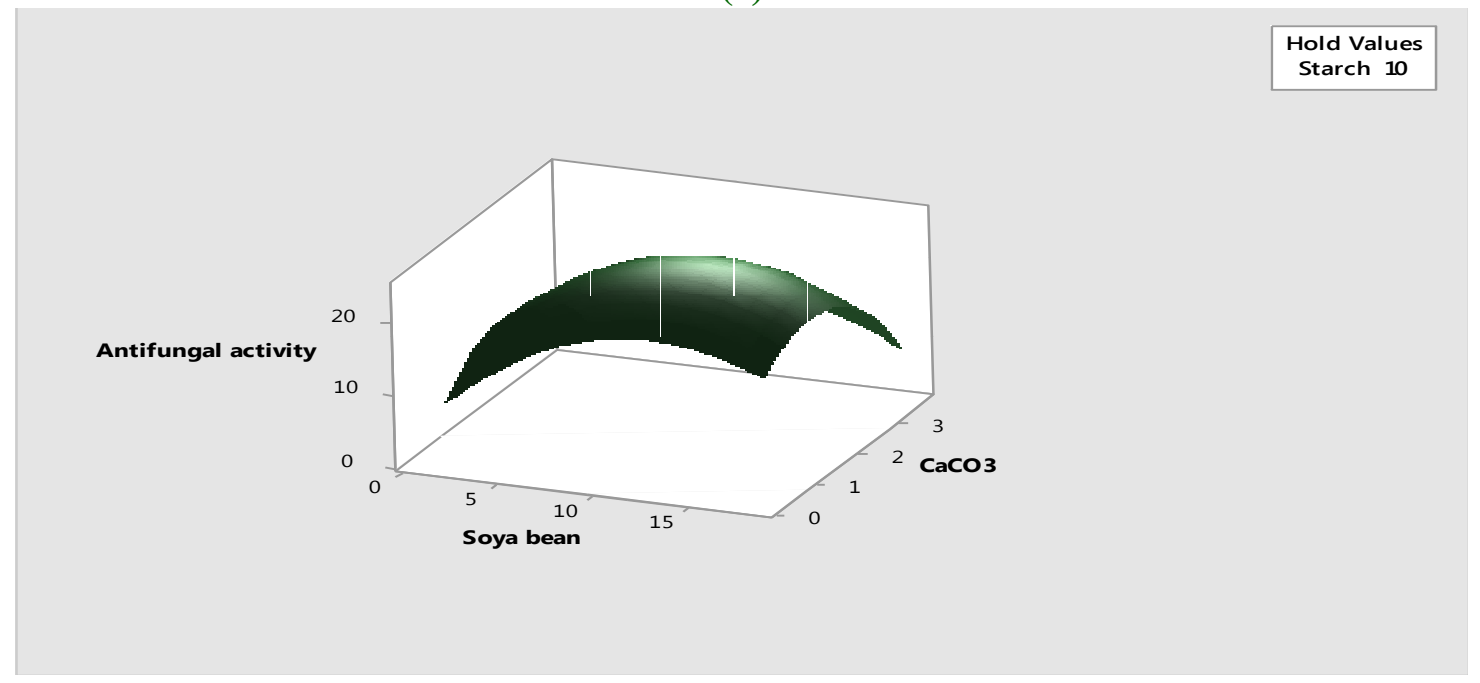

(f)

Fig.7 Response surface plots (3D) and contour plots (2D) showing the individual and interactive effect of variables on the antifungal activity of Janibacter sp. RC18 against C. coccodes. $(\mathrm{a}, \mathrm{b})$ effect of soybean meal and starch. (c,d) effect of starch and $\mathrm{CaCO}_{3}$ $(e, f)$ effect of soybean and $\mathrm{CaCO}_{3}$ ) 


\section{Int.J.Curr.Microbiol.App.Sci (2020) 9(4): 284-302}

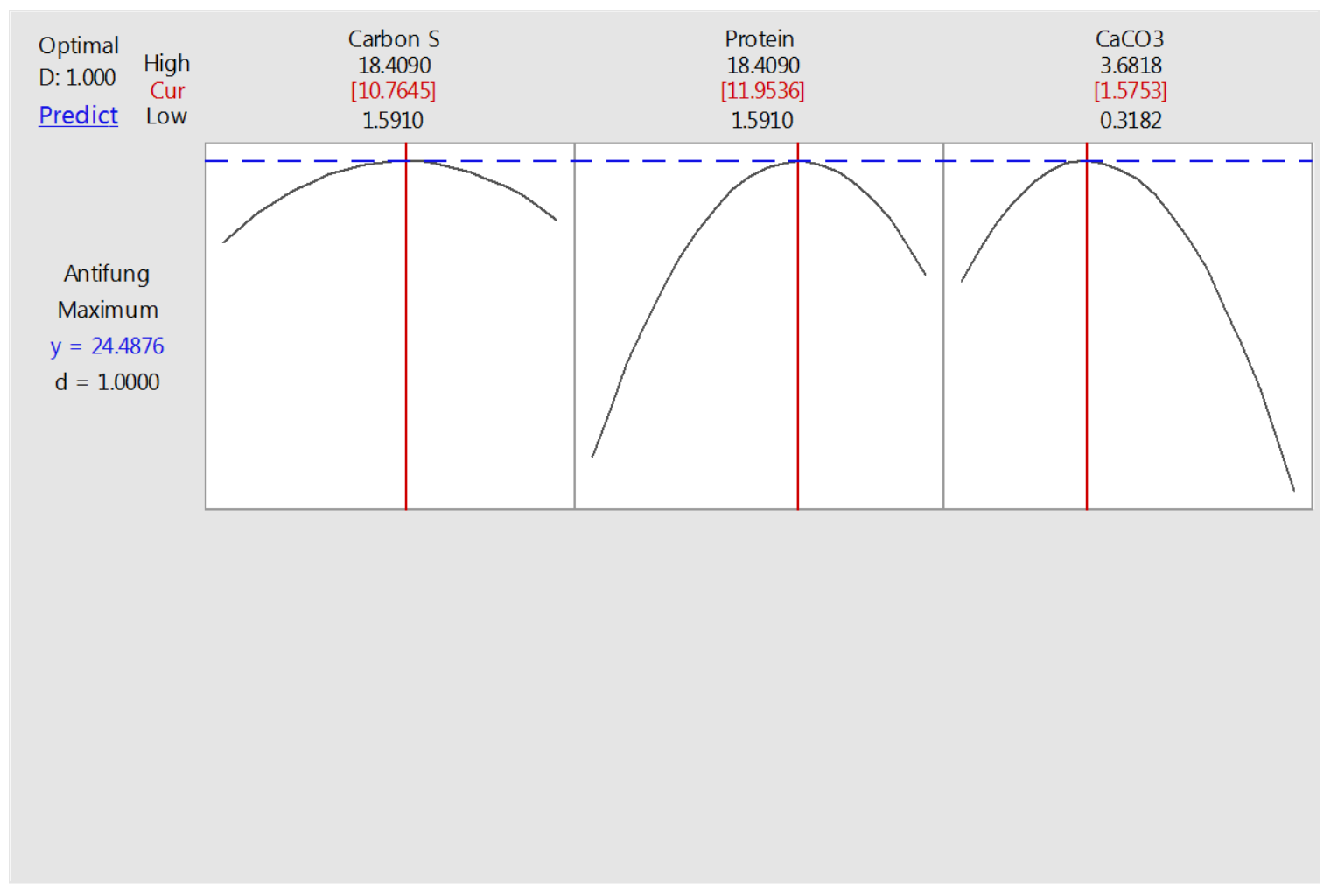

Fig.8 Optimal plot

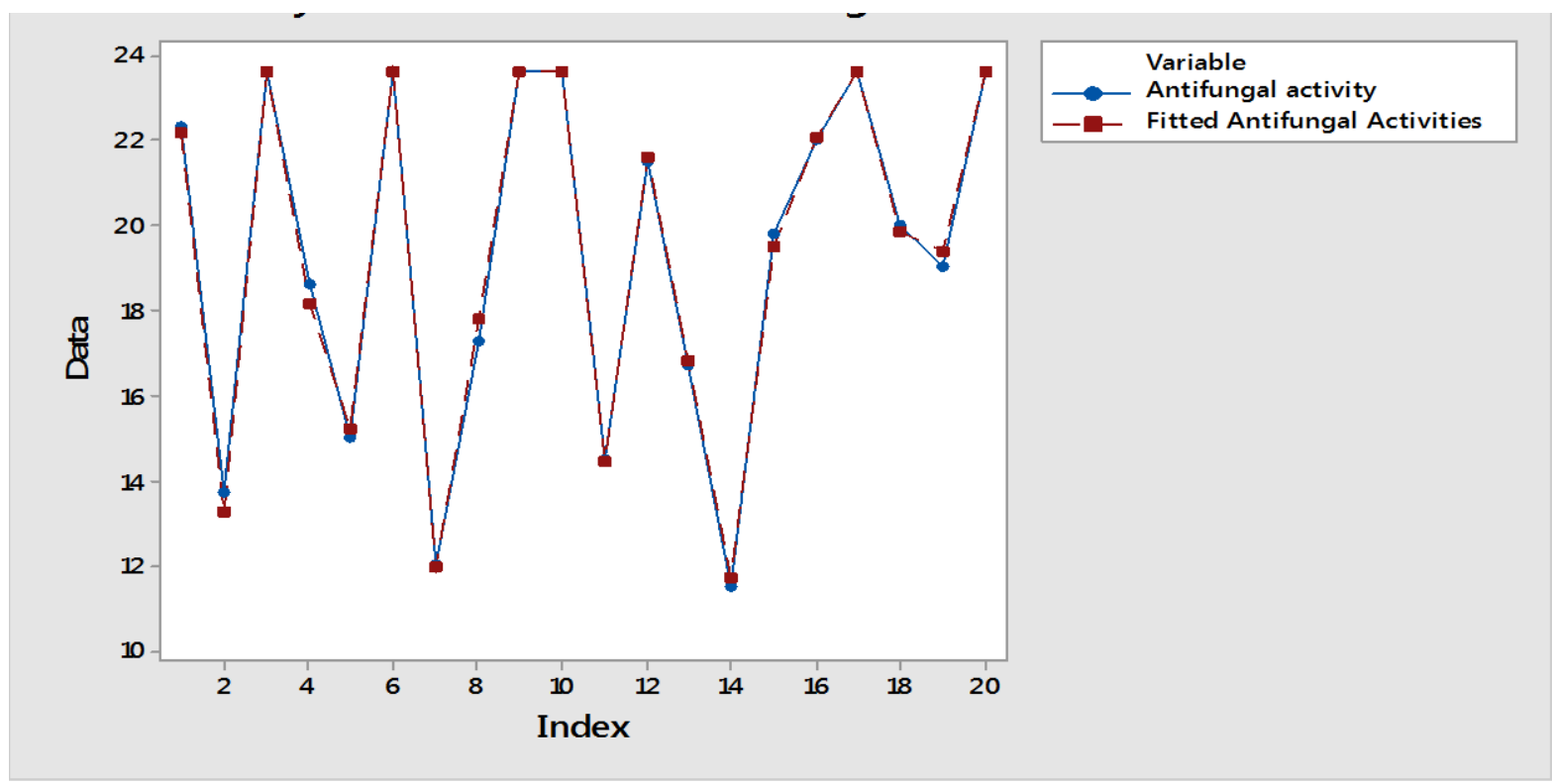

Fig.9 Parity plot of the observed and predicted antifungal activity 


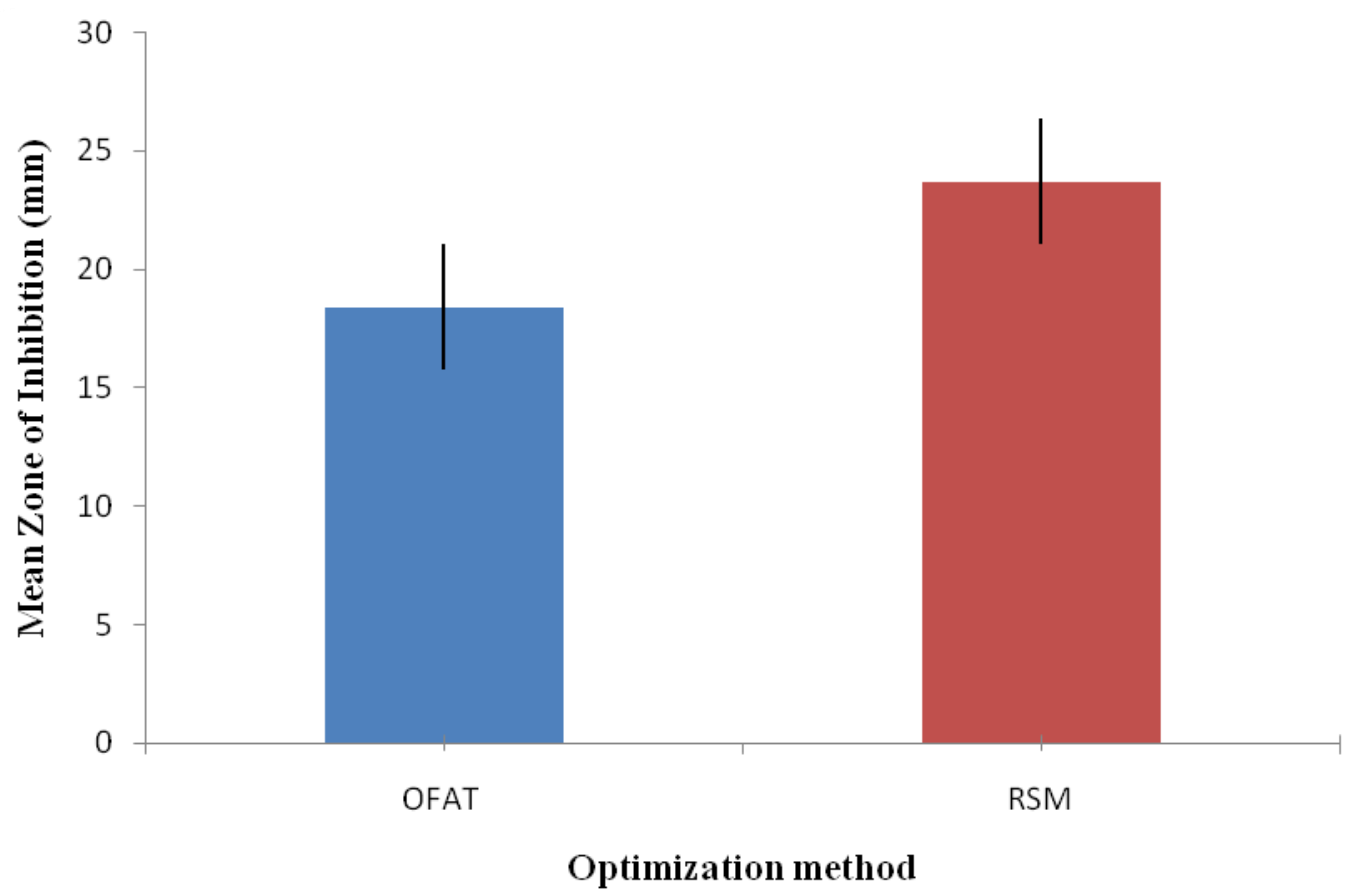

Fig. 10: Comperativemedium optimization for anifungal production by Janibacter sp. Strain RC18 using OFAT and RSM

Thus, the RSM model was validated with good correlation as the predicted results match well with the experimental results obtained using RSM optimized value.

\section{Validation of the experiment}

To test for the validity of the models in predicting the optimal response, validation experiments were carried out at the predicted optimal value.

The result showed that the maximum antifungal activity against $C$. coccodes was $23.7 \pm 0.09 \mathrm{~mm}$ which was close to the predicted response value $24.49 \mathrm{~mm}$. The result of RSM optimization revealed that antifungal metabolite production was enhanced by $22.33 \%$ when compared to the OFAT SS medium (Soybean meal Starch broth) $18.4 \pm 0.06 \mathrm{~mm}$ as shown in Fig. 10 .

Antifungal bioactive metabolite production is a complex process, it does not only depend on a potent strain but also on media composition and physical fermentation conditions such as $(\mathrm{pH}$, temperature and time). Minor modification of the fermentation media composition does not only enhance production of bioactive compounds but also leads to changes in metabolic profile of the strain.

Fermentation time is an important factor that affects the antifungal metabolite production, the result obtained showed a gradual increase in antifungal production from day 3 incubation period to day 7 which was recorded as the optimum beyond this fermentation period was a decline in antimetabolite production. This might be explained by activities taking place at different fermentation phases according to Wang (2011), the first phase pre-fermentation phase (growth phase), the second phase of rapid production of secondary metabolite accumulation, and the third phase (post fermentation) phase of slow accumulation of metabolite. This result is in agreement with investigations of Sharon et al., (2014) which 
recorded incubation day 7 as optimum for antimetabolite production in Streptomyces sp. KOD10. Khattab et al., (2016) and Aliero et al., (2018) also reported optimum antifungal production for Streptomyces sp. at incubation day 7 .

On the other hand, maximum antifungal production was obtained at temperature $30^{\circ} \mathrm{C}$ for Janibacter sp RC18, the decline afterward up to $45^{\circ} \mathrm{C}$ where antifungal metabolite production was not recorded. Similarly, Bindu et al., (2018) showed that temperature $30^{\circ} \mathrm{C}$ was optimum for secondary metabolism in Streptomyces lavenducolor VHB-9, Singh and Roymon (2014) also recorded that optimum temperature for antimicrobial metabolite production in Streptomyces sp. isolated from soil was $30^{\circ} \mathrm{C}$.

The maximum antifungal production by Janibacter sp. RC18 was at an initial pH 8, high acidity ( $\mathrm{pH} 3$ and 4) and high alkalinity ( $\mathrm{pH} 10)$ inhibited antifungal metabolite production in the studied strain. Most actinomycetes are neutrophilic, therefore have optimum $\mathrm{pH}$ range between $7-8$ (Augustine, 2005).

Exploring the effect of carbon source on antifungal metabolite production in Janibacter sp. RC18 showed that minimal production of antifungal metabolite production was obtained with glucose and fructose which are readily utilizable carbon that are preferable for rapid growth of most microorganisms while the best carbon source for the studied strain was recorded to be starch a complex carbon source. Singh et al., (2017) reported starch as the best carbon source for enhancement of antifungal metabolite production in Streptomyces sp. Also in agreement with the result is the investigations of Abdelwahed et al., (2012) showed that starch was the best carbon source for Streptomycescyaneus DN37.
In a similar way, investigations on the effect of nitrogen sources on regulation of antifungal metabolite production on the studied strain revealed that soybean meal was the best nitrogen source at which maximum biosynthesis of antifungal metabolite production was attained. In concordance with this result is the report of Bhavana et al., (2014) which reported soybean meal as the most excellent nitrogen source for Streptomyces carpaticus. The reason might be that soybean meal as a complex nitrogen source is not easily utilizable and also contains many amino acids which might act as precursor in secondary metabolism (Augustine, 2005).

\section{Optimization by response surface methodology using central composite design}

In the statistical optimization the focus was on the nutritional factors whereby soybean meal (nitrogen source) and starch (carbon source) which were found significant from the result of preliminary optimization using OFAT, $\mathrm{CaCO}_{3}$ which enhances the activity of rare and slow growing actinomycetes can inhibit secondary metabolism at high concentration (Yi et al., 2015). CCD was used by RSM, the analysis helped to find out interaction between variables and optimum combination of the three nutritional variables starch, soybean meal and $\mathrm{CaCO}_{3}$.

\section{Response surface quadratic model}

In the regression analysis, the significance of every coefficient that showed the interaction among the independent variables (starch, soybean meal and $\mathrm{CaCO}_{3}$ ) were determined by $F$ - test and $\mathrm{p}$ values of the Fisher's test. The linear regression coefficient terms of starch and soybean meal showed great impact on antifungal metabolite production, they had positive and significant $(p=0.000)$ effect, 
which implies that production increased as parameter values increased. While the linear term of $\mathrm{CaCO}_{3}$ had negative and insignificant $(p=0.349)$ effect which means that antifungal production decreased as parameter values increased. This is supported by the fact that $\mathrm{CaCO}_{3}$ inhibits secondary metabolisms (Yi et al., 2015).

Also the quadratic terms of coefficient were all negatively significant which implies that increase in concentration of starch, soybean and $\mathrm{CaCO}_{3}$ beyond a certain concentration decreases the antifungal metabolite production. For the interactive terms of coefficient, the interaction between starch and $\mathrm{CaCO}_{3}\left(\mathrm{X}_{1} \mathrm{X}_{3}\right)$, soybean and $\mathrm{CaCO}_{3}\left(\mathrm{X}_{2} \mathrm{X}_{3}\right)$ were significant while interaction between starch and soybean $\left(\mathrm{X}_{1} \mathrm{X}_{2}\right)$ were not significant which implies that increase in parameters result in decrease in antifungal metabolite production.

The ANOVA result described the statistical analysis for significances of all factors, the adequacy of the model was analysed by the $R^{2}$ coefficient, correlation and model significance ( $F-$ value). The quality of the fit of the equation is described by $R^{2}$, a good $R^{2}$ should be $80 \%$ and above (Kocheki et al., 2009). The result obtained $R^{2}$ for antifungal metabolite production was 0.9968 , this is an indication that the model could explain about $99.68 \%$ of the variability and it was attributed to independent variables.

The good of fit was determined by $R^{2}$ adj, in this study $R^{2}$ adj of 0.994 is an indication of agreement of a good model among the obtained and predicted values for response output (Danbaba et al., 2015). Model significance $(F-$ value) is a measure of variation of data around the mean. The probability value of $\left(P_{\text {model }}>F\right)$ of less than 0.05 implies that the model is statistically significant, which means present model can serve as good prediction of experimental result (Yun et al., 2018; Wang et al., 2018).

However, the coefficient of variation low level $(\mathrm{CV}=3.24 \%)$ suggested that these experiment were reliable and precise. Axial Points with coded value $(0)$ were repeated six times in order to estimate the pure error for the lack of fit (LOF) tested. Insignificant LOF is the most desirable and can be used for predictions. This model produced LOF that is not significant $\left(P_{\text {model }}>F\right)$ at 0.0509 .

\section{Residual plot}

The residual plot is the most analytical tool for the model, the linearity in the error pattern of the normal probability plot is an indication that there were no signs of problems in the data, this verified the normality regression model. The plots of residual versus fitted value implies homoscendasiticity (constant variance), the randomly scattered points spread around 0 without obvious shape being made by this points indicates assumption of the error having zero mean and equal variance. Furthermore, the dumbbell shape of the histogram plot of frequency versus residual suggested normality of the design also the plot of residual versus observation order shows that the residual is symmetric and have a constant variance. This implies that the result from this model can be used for inferential purpose following the limit theorem (Montgomery, 1997; Tsai et al., 1998).

\section{Response analysis}

The result of $3 \mathrm{D}$ indicates that concentration of the three nutritional variables should not exceed a certain concentration so as not repress antifungal production. The elliptical shaped 2D contour plot of interactive terms of starch and $\mathrm{CaCO}_{3}$, and soybean and starch depicts that their interactive terms were 
significant, the circular shape of the soybean and $\mathrm{CaCO}_{3}$ means insignificant interactive term. These results are in agreement with the results obtained in Table 4.

\section{Validation of experiment}

Validation of the result was carried out using the optimal nutritional variables condition as follows starch $10.76 \mathrm{~g} / \mathrm{l}$, soybean meal 11.95 $\mathrm{g} / \mathrm{l}$ and $\mathrm{CaCO}_{3} 1.57 \mathrm{~g} / \mathrm{l}$ in a shake flask condition. The maximum antifungal activity obtained experimentally was $23.7 \pm 0.09 \mathrm{~mm}$ diameter of inhibition as against $24.49 \mathrm{~mm}$ predicted. This is in agreement with the model prediction, hence, the model developed was considered to be reliable and precise for predicting the enhanced antifungal metabolite production in Janibacter sp strain RC18. Also in comparison with OFAT optimized medium there was about $22.33 \%$ increase in antifungal metabolite production which means RSM is a good tool for optimization.

Conclusion of the study is as follows:

To enhance the antifungal metabolite production in Janibacter sp. RC18, preliminary optimization was carried out using OFAT to select significant nutritional variables. Thereafter, RSM using CCD was adopted to optimize the selected significant fermentation media components (starch, soybean meal and $\mathrm{CaCO}_{3}$ ). The statistical optimization resulted in antifungal activity of $23.7 \pm 0.09 \mathrm{~mm}$ against $C$. coccodes which was $22.33 \%$ higher than that of OFAT optimized medium $(18.4 \pm 0.06 \mathrm{~mm})$. The predicted values were in excellent correlation with experimental values hence validating the experiment and confirming accuracy of the model.

\section{References}

Abdalwahed, N. A.M., Abdallah, N. A., ElGhawas, D. E., Badr El-Din, S. M. and El-
Diwany, A. I.( (2012) Isolation, identification and optimization of antimicrobial metabolites produced by soil derived actinomycetes. Egyptian Journal of Biology (Bot). 8(2):205-217.

Achari, G. A, and Ramesh, R. (2014) Diversity, biocontrol, and plant growth promoting abilities of xylem residing bacteria from solanaceous crops. International Journal of Microbiology. 14. Article ID: 296521.

Ahmad, F., Ahmad, A. I. and Khan, M. S. (2008). Screening of free-living rhizospheric bacteria for their multiple plant growth promoting activities. Microbiology Research. 163, 173-181. doi:10.1016/j.micres.2006.04.001.

Ahsan, T., Chen, J., Wu, J. And Ifran, M. (2017a). Application of response surface methodology for optimization of medium components for production of secondary matabolites from Streptomyces diastatochromogenes. EX852460. AMB Express. 7 (96) 1-10.

Ahsan, T., Chen, J., Zhao, X., Irfan, M., and Wu, $Y$ (2017b) Screening, identification and optimization of fermentation conditions and extraction of secondary metabolites for the biocontrol of Rhizoctonia solani AG.3. Biotechnology and Biotechnological Equipment. 13(1): 91-98.

Aliero, A.A., Adam, A.S., Ntuluma, I., Bagudo, A. S., Kudu, A. A. B., Ondieki, M. C., Jega, S. A., Odda, J. and Okech, M. A. (2018). Molecular characterization and optimization of bioactive compounds production of three actinomycetes isolated from waste dump soil from Western Uganda. Curr tr Biotechnol and Pharm. 12(3)230-244.

Augustine, S. K., Bhavsar, S. P. and Kapadnis, B. P. (2005). A non-polyene antifungal antibiotic from Streptomyces albidoflavus PU 23. Journal of Bioscience. 30(2), 201211.

Barry, A.L. and Thornsberry, C. (1985). Susceptibility tests: diffusion test procedure. In Manual of Clinical Microbiology, 4th edn., eds. Ballows EA, Hawsler Jr. WJ, Shadomy HI. Washington DC: American Society of Microbiology. ISBN 0-914826-65-4. pp: 978-987. 
Bhavana, M., Talluri, V. P., Kumar, K. S. and Rajagopal, S.V. (2014). Optimization of culture conditions of Streptomyces carpaticus (mtcc-11062) for the production of antimicrobial compound. International Journal of Pharmacy and Pharmaceutical Science. 6 (8), 281-285.

Bindu, H. B., Munabanti, R.K,, Muvva, V., Naragani, K. and Indupalli, M. D. (2018). Optimization, isolation and characterization of bioactive compounds from Streptomyces lavenducolor VHB-9. Asian Journal of Pharmaceutical and Clinical Research. 11(8) 361-368.

Bundale, S., Deovrat, B., Nashikkar, N., Kadam, T. and Upadhyay, A. (2015). Optimization of Culture Conditions for Production of Bioactive Metabolites by Streptomyces spp. Isolated from Soil. Advanced Microbiology. 5: 441-451.

Danbaba, N., Badau, M. and Nkama, I. (2015). Application of Response Surface Methodology (RSM) and Central Composite Design (CCD) to Optimize Minerals Composition of Rice-Cowpea Composite Blends during Extrusion Cooking. International Journal of Food Science Nutrition Engineering. 5(1):40-52.

EEA (2005) Environment and health. European Environmental Agency. EEA Report No. 10.

http://www.eea.europa.eu/publications/tech nical-report-2005-8. assessed 12 January 2019.

FAO (Food and Agriculture Organization of United nations) (2017). Strategic Work of FAO for sustainable food and agriculture. Available at www. fao.org/publication. Accessed $23^{\text {rd }}$ June 2018.

Hamada, M., Tamura, T., Yamamura, H., Suzuki, K. and Hayakawa, M. (2013). Demequina flava sp. nov. and Demequina sediminicola sp. nov., isolated from sea sediment. International Journal of Systematic Evolutionary Microbiology. 63: 249-253.

Imamura, Y., Ikeda, M., Yoshida, S. and Kuraishi, H. (2000). Janibacter brevis sp. nov., a new trichloroethylene-degrading bacterium isolated from polluted environments. International Jouurnal of Systematic Evolutionary Microbiology. 50: 1899-
1903.

Kageyama, A., Takahashi, Y., Yasumoto-Hirose, M., Kasai, H., Shizuri, Y. and Omura, S. (2007). Janibacter corallicola sp. nov., isolated from coral in Palau. Journal of Geneneral and Applied Microbiology. 53: 185-189.

Khattab, A.I., Eltahir, H., Babiker, and Humodi, A.S. (2016). Streptomyces: isolation, optimization of culture conditions and extraction of secondary metabolites. International Current Pharmaceutical Journal, 5: 27-32.

Koocheki, A., Taherian, A.R., Razavi, S.M.A., and A. Bostan (2009). Response surface methodology for optimization of extraction yield, viscosity, and hueand emulsion stability of mucilage extracted from Lepidium perfoliatum seeds. Food Hydrocolloids. 23: 2369-2379. doi:10.1016/j.foodhyd. 2009.06.014.

Li, J., Long, L. J., Yang, L. L., Xu, Y., Wang, F. Z., Li, Q. X., Zhang, S. and Li, W. J. (2012). Janibacter alkaliphilus sp. nov., isolated from coral Anthogorgia sp. Antonie van Leeuwenhoek, 102: 157-162.

Martin, K., Schumann, P., Rainey, F. A., Schuetze, B. and Groth, I. (1997). Janibacter limosus gen. nov., sp.nov; a new Actinomycete with meso-diaminopimelic acid in the cell wall. International Journal of Systematic Baccteriology.47:529-34.

Montgomery, D. C. (1997). Design and Analysis of Experiments: Chapter 13, 4th edn., John Wiley and Sons, USA.

Nimaichand, S., Devi, A.M., Tamreihao, K., Ningthoujam, D.S. and Li, W-J (2015) Actinobacterial diversity in limestone deposit sites in Hundung, Manipur (India) and their antimicrobial activities. Frontier in Microbiology. 6:413. doi: 10.3389/fmicb.2015.00413.

Osaro-Matthew, R.C., Ire, F.S. and FrankPeterside N. (2020) Screening of actinomycetes from Turmeric (Curcuma longa L.) and ginger (Zingiber officinale) rhizosphere for antifungal activity. Journal of Advances in Microbiology. 20(2) 18-28.

Sharon, S. F. B., Daniel, R. R. and Shenbagarathai, R. (2014) Optimization of antibiotic production by marine 
actinomycetes streptomyces sp KOD10. International Journal of Pharmacy Pharmaceutical Science. 6 (2): 506-510.

Shivaji, S., Chaturvedi, P., Begum, Z., Pindi, P. K., Manorama, R., Padmanaban, D. A., Shouche, Y. S., Pawar, S., Vaishampayan, P. et al., (2009) Janibacter hoylei sp. nov., Bacillus isronensis sp.nov. and Bacillus aryabhattai sp. nov., isolated from cryotubes used for collecting air from the upper atmosphere. International Journal of Systemic Evolution Microbiology. 59: 2977-2986.

Singh, C., Parmar, R. S., Jadon, P. and Kumar, A. (2017). Optimization of Cultural Conditions for Production of Antifungal Bioactive Metabolites by Streptomyces spp. Isolated from Soil. International Journal of Current Microbiology and Applied Science. 6(2): 386-396.

doi: http://dx.doi.org/10.20546/ijcmas.2017.602. 043

Singh, P. and Roymon, M. G. (2017) Antibiotic potential of soil actinomycetes under influence of physical and nutritional parameters. Indian Journal of Science and Research. 13(2): 203-207.

Snedecor, G.W. and Cochran, W.G. (1980). Statistical Methods, 7th Ed., Iowa State University Press, Ames, IA.

Tsai, C. T., Cai, Z. and Wu, X. (1998). The examination of residual plots. Statistica Sinica, 8: 448-468.

Wang, J. (2011). Study on the Antagonistic Actinomycetes for Biocontrol of Plasmodiophora brassicae, Dissertation, Sichuan Agricultural University.

Wang, L. Zhang, M., Li, Y., Cui, Y., Zhang, Y., Wang, Z., Wang, M. and Huang, Y. (2018) Application of response surface methodology to optimize the production of antimicrobial metabolites by Micromonospora Y15. Biotechnology and Biotechnological Equipment. 31(5)10161025 .

Yi, J. S., Kim, M., Kim, S. and Kim, B. (2015). Effects of sucrose. Phosphate and Calcium carbonate on production of pikromycin from Streptomyces venezuelae. Journal of Microbiology and Biotechnology. 25(4): 496-502.

Yoon, J. H., Lee, K.C., Kang, S.S., Kho, Y.H., Kang, K.H. and Park, Y. H. (2000). Janibacter terrae sp. nov., a bacterium isolated from soil around a wastewater treatment plant. International Jouurnal of Systematic Evolutionary Microbiology. 50:1821-7.

Yoon, J. H., Lee, H. B., Yeo, S. H. and Choi, J. E. (2004). Janibacter melonis sp. nov., isolated from abnormally spoiled oriental melon in Korea. International Journal of Systematic Evolutionary Microbiology. 54, 1975-1980.

Yun, T.Y., Feng, R. J., Zhou, D. b., Pan, Y. Y., Cheng, F. Y., Wang, F, Yin, L. Y., Zhang, Y. D. and Xie, J. H. (2018). Optimization of fermentation condition through response surface methodology for enhanced antibacterial metabolite production from Streptomyces sp. 1-14 from cassava rhizosphere. PLoS One 13(11): e0206497.

Zhang,G., Ren, H., Wang, S., Chen, X., Yang,Y., Zhang, Y. and Jiang. Y. (2014). Janibacter indicus sp. nov., isolated from hydrothermal sediment of the Indian Ocean. International Journal of Systematic Evolutionary Microbiology. 64, 23532357. DOI 10.1099/ijs.0.059527-0.

\section{How to cite this article:}

Ruth Chiamaka Osaro-matthew, Francis Sopuruchukwu Ire and Nnenna Frank-peterside. 2020. Optimization of Nutritional Variables Using Response Surface Methodology for Enhanced Antifungal Metabolite Production by Janibacter sp. RC18 from Turmeric Rhizosphere. Int.J.Curr.Microbiol.App.Sci. 9(04): 284-302. doi: https://doi.org/10.20546/ijcmas.2020.904.035 